\title{
ELECTRICAL CHARACTERISTICS OF DENDRITES AND DENDRITIC SPINES IN INTRACELLULARLY STAINED CA3 AND DENTATE HIPPOCAMPAL NEURONS ${ }^{1}$
}

\author{
DENNIS A. TURNER ${ }^{2}$ AND PHILIP A. SCHWARTZKROIN \\ Department of Neurological Surgery, University of Washington RI-20, Seattle, Washington 98195
}

Received January 25, 1983; Revised May 6, 1983; Accepted May 27, 1983

\begin{abstract}
Theoretical parameters of synaptic efficacy were studied in a detailed cable model of in vitro hippocampal neurons. CA3 pyramidal cells $(n=9)$ and dentate granule neurons $(n=6)$ were injected with horseradish peroxidase (HRP) after brief physiological analysis. The dendrites of these HRP-stained neurons were measured and approximated by a series of cylindrical segments. Specific electrical values of the neurons were calculated on a steady-state basis, using a cable analysis of the dendritic segments. The evaluation was expanded to include idealized dendritic spines. Average spine dimensions were determined by electron microscopic measurements. The density distribution of spines was patterned after reported Golgi measurements of similar neurons.

The average electrotonic length of the CA3 apical dendrites was determined to be 0.69 length constant. These CA3 neurons were not well approximated by a single equivalent cylinder coupled to a soma (E-C model). The dentate granule cells exhibited an average electrotonic length of 1.12 length constants and could be adequately represented by the E-C model. Synaptic efficacy was estimated by the transfer of either charge or steady-state voltage from a spine input to the soma. Charge transfer varied as a function of the electrotonic distance from the soma to the input site. Voltage transfer, however, did not vary as a simple function of electrotonic distance.

Voltage and charge transfer averaged less than $10 \%$ loss across the dendritic spine neck. These calculations, based on specific neuronal anatomy, predict that dendritic spines do not significantly attenuate steady-state electrical signals.
\end{abstract}

In the hippocampus, most excitatory synaptic inputs terminate on dendritic spines (Laatsch and Cowan, 1966; Scheibel and Scheibel, 1968; Englisch et al., 1974; Meyer and Ferres-Torres, 1978; Amaral and Dent, 1981). It has been suggested that spines serve to influence and possibly modulate synaptic inputs (Diamond et al., 1971; Rall, 1974; Swindale, 1981; Crick, 1982; Gray, 1982; Rinzel, 1982; Koch and Poggio, 1983). This influence may consist of either isolating adjacent spines from each other electrically or attenuating the input. Because of the small size and remote location of most dendritic spines, direct testing of these hypotheses is not feasible. Thus, indirect

\footnotetext{
${ }^{1}$ We thank Dennis Kunkel for his invaluable EM assistance. This research was supported by National Institute of Neurological and Communicative Disorders and Stroke Grants NS07144, NS04053, and NS15317 (P. A. S.), as well as by National Science Foundation Grant BNS7915115.

${ }^{2}$ To whom correspondence should be addressed, at Department of Neurosurgery, 112N, VA Medical Center, 54th Street and 48th Avenue South, Minneapolis, MN 55417.
}

methods are necessary to evaluate the spread of electrical signals from spines to the soma.

Two important factors defining the degree of spine attenuation have been presented by Rall (1974). These are the spine stem resistance $\left(R_{s s}\right)$ and the input resistance into the dendrite at the attachment of the spine $\left(R_{d}\right)$. The ratio of these two resistances defines the voltage attenuation across the spine neck. The factor $R_{s s}$ can be estimated from reported spine dimensions (as measured using electron microscopy). $R_{d}$, however, is determined by the branching characteristics and electrical membrane parameters of the neuron. Thus, an analysis of the functional attributes of spines involves a detailed electrical evaluation of neuronal architecture (see also Koch and Poggio, 1983). The present study follows Rall's (1959) theoretical outline and is based on specific dendritic dimensions which have been derived from intracellular injection of horseradish peroxidase (HRP).

This report presents a theoretical evaluation of synaptic efficacy, as viewed in a steady-state model. Two 
processes may be defined in evaluating the propagation of postsynaptic signals. The first process involves the predicted signal conduction across the spine and into the adjacent dendritic shaft. The second process consists of the electrical transfer from the site of spine attachment on the dendrite to the soma or axon hillock. We have used the Rall cable model (1959) to derive estimates of synaplic efficacy, based on these processes. Values of steady-state voltage transfer and charge transfer to the soma were calculated, from an assumed spine input site.

Most signal attenuation in this detailed cable model occurred in the passive conduction through dendrites, rather than across the spine neck. Charge transfer to the soma depended largely on the electrotonic distance from soma to input site. Steady-state voltage transfer did not vary as a simple function of the electrotonic distance to the input site. These results, based on actual dendritic anatomy, confirmed earlier analytical predictions of the equivalent cylinder cable model (Rall and Rinzel, 1973). It was also found, however, that dendritic branching often does not follow the equivalent cylinder assumption. Thus, the evaluation of single inputs onto specific dendritic branches or spines may require detailed analysis of neuronal architecture. A preliminary abstract of this work has been published (Turner, 1982).

\section{Materials and Methods}

\section{Experimental preparation}

Guinea pig hippocampal slices, 400 to $450 \mu \mathrm{m}$ thick, were maintained "in vitro" as detailed previously (Schwartzkroin, 1975; 'Turner and Schwartzkroin, 1980). Thin wall glass electrodes with an intraluminal fiber were filled with a solution of HRP (type VI, Sigma, in $0.2 \mathrm{M} \mathrm{KCl}$, buffered to $\mathrm{pH} 8.6$ with Tris). These electrodes ranged in resistance from 125 to 150 megohms and did not require bevelling. Intracellular recordings were limited to the cell body layers of the CA3 and dentate regions. Criteria for acceptable impalements were: a minimum spike height of $55 \mathrm{mV}$, intact synaptic response, and repetitive firing in response to intracellular depolarizing pulses. The neuronal input resistance $\left(R_{N}\right)$ was estimated from the voltage response following the injection of hyperpolarizing current pulses ( 0.1 to 0.5 $\mathrm{nA}$ ). The amplifier bridge was balanced after intracellular penetration. This procedure eliminated the transients at both the beginning and end of the current pulse. The longest time constant $\left(\tau_{0}\right)$ was estimated from the terminal linear portion of the normalized charging function $\left(1-V / V_{m}\right)$ (Wong and Prince, 1981).

After physiological analysis, HRP was iontophoresed into the neuron. Cell staining required $1-$ to $2-\mathrm{nA}, 250-$ msec pulses delivered at $2.5 \mathrm{~Hz}$, for at least $20 \mathrm{~min}$. Immediately after HRP injection the slices were placed in cold fixative, consisting of $1.25 \%$ glutaraldehyde and $1 \%$ formaldehyde buffered to $\mathrm{pH} 7.6$. After 1 to $2 \mathrm{hr}$, slices were cut into $75-\mu \mathrm{m}$ frozen sections. These sections were then incubated in $0.5 \% \mathrm{CoCl}_{2}$ (Tris buffer, $\mathrm{pH}$ 7.6) for $15 \mathrm{~min}$ and $0.01 \% \mathrm{H}_{2} \mathrm{O}_{2}$ and $0.05 \%$ diaminobenzidine for another $15 \mathrm{~min}$. The sections were mounted in phosphate buffer but were neither dehydrated nor cleared, to minimize shrinkage. Linear shrinkage was calculated by making parallel knife cuts on slices, $100 \mu \mathrm{m}$ apart. The distance between cuts was measured at $\times 100$ before fixation and again after the entire processing. Shrinkage averaged $4.0 \pm 0.5 \%$ (SEM) for 15 measurements. No corrections for shrinkage were used in the subsequent neuronal measurements.

Camera lucida drawings were constructed at a magnification of $\times 1500$, using a Leitz microscope and drawing tube. The soma was approximated as a sphere, an ellipsoid, or an irregular geometric body (Mannen, 1966). The length, diameter, and vertical extent of each dendritic branch were measured between branch points. The out of plane (vertical) dimensions were corrected for the refractive index of the mounting media. All visible parts of the dendritic tree on adjacent sections were incorporated in the reconstruction of each HRP-stained neuron. The measured neuronal arborization was split into a series of dendritic segments. These segments were cylindrical approximations to the actual dendritic branches. If the diameter of a dendrite varied by greater than $10 \%$, then the branch was more finely divided into several segments. A centrifugal ordering system was devised by which each neuron was entered into a computer (PDP Lab8E with $32 \mathrm{~K} 12$-bit words of memory) segment by segment. Because of the large number of segments per neuron (400 to 1200), floppy discs were used for intermediate storage.

\section{Calculations}

Reconstruction of somatic inputs. A cylindrical dendritic segment can be represented by a finite length of coreconducting cable (Norman, 1972; Rall, 1959, 1977). Each segment of measured neuron was therefore characterized by a geometric length, a uniform diameter and input and terminating conductances or admittances (Fig. $1 A$ ). The steady-state condition required only two free variables:

1. The specific internal or core resistivity $\left(R_{i}\right.$, in ohm$\mathrm{cm})$.

2. The terminating conductance of the most distal segments ( $\mathrm{B}$, dimensionless). This factor was normalized with respect to the input conductance of a semi-infinite cable of the same diameter and membrane properties.

Certain neuronal measurements were considered as constants in the calculations. These included the experimentally determined input resistance $\left(R_{N}\right)$, the dendritic segment dimensions, and the dendritic spine dimensions (see below). The specific membrane resistivity $\left(R_{m}\right.$, ohm- $\mathrm{cm}^{2}$ ) was determined using these constant values. $R_{m}$ possessed only one unique value for each combination of the two free variables, $R_{i}$ and $\mathrm{B}$, given the neuronal measurements (Turner and Schwartzkroin, 1980).

Assumptions required for this segmental cable analysis included the following:

1. The cable segments were assumed to consist of uniform, passive membrane, which was ohmic.

2. The extracellular space was assumed to have infinite conductivity. This allowed the specific geometry of branch angles and the external resistivity to be ignored.

3. The soma was treated as a lumped, isopotential region.

4. There was continuity of current and voltage at branch points and at the junction with the soma. 
A
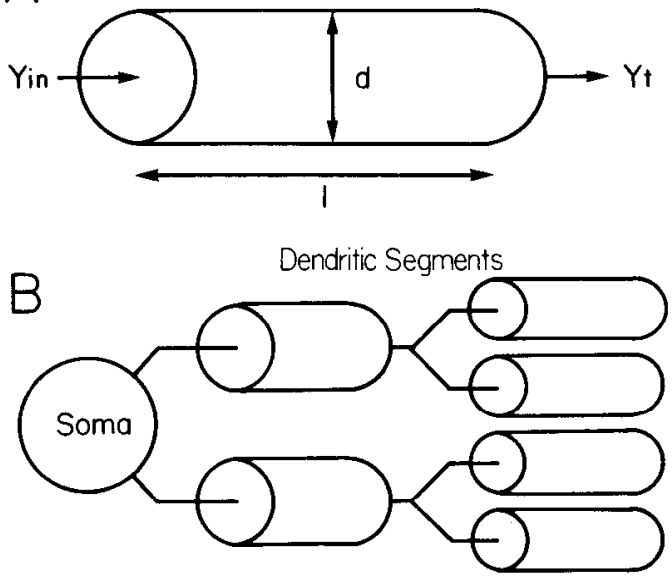

C

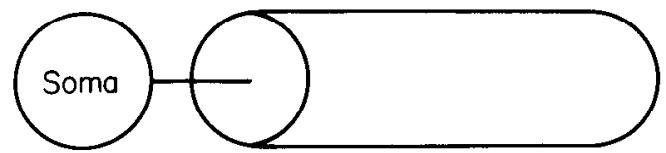

Figure 1. A, A single cable segment. The segment approximates a short piece of dendrite and possesses a length $(l)$ and uniform diameter $(d)$. The input and output admittances $\left(Y_{\text {in }}\right.$ and $\left.Y_{t}\right)$ or conductances $\left(G_{i n}\right.$ and $\left.G_{t}\right)$ are characteristic for each segment. $B$, A segmental portrayal of a neuron. The cable segments are connected to each other and to the soma in the anatomically observed order. $C$, A representation of an equivalent cylinder coupled to a soma. The cylinder portion represents all of the lumped dendritic elements.

These assumptions have been extensively discussed by Rall (1959, 1977).

All of the calculations were based on a steady-state model. $R_{i}$ was assumed to be $75 \mathrm{ohm}-\mathrm{cm}$. This value lies in the midpoint of the range assumed by others (Jacobsen and Pollen, 1968; Rall, 1959, 1977) and near an estimated value of $70 \mathrm{ohm}-\mathrm{cm}$ for motoneurons (Barrett and Crill, 1974a). B (for the terminating segments only) was assumed to be either zero or one. $B=0$ signified a "sealedend" termination to a segment. $B=1$ represented the terminating conductance as equal to that of a semiinfinite cable.

The calculations considered one branch point (or junction of segments) at a time. The initial order of evaluation was from distal to proximal (from right to left in Fig. $1 B$ ). For the most peripheral branches only, the terminating $B$ value was assumed, as described above. At each junction, the electrotonic length for the daughter branches was calculated first:

$$
\mathrm{X}=l / \lambda, \lambda=\sqrt{\frac{\mathrm{d} \times R_{m}}{4 \times R_{i}}}
$$

where $l$ was the geometric length of the segment, $d$ the diameter, lambda $(\lambda)$ the length constant, and $\mathrm{X}$ the resulting electrotonic length of the segment. The input conductance $\left(G_{i n}\right.$ or $Y_{\text {in }}$, as in Fig. $\left.1 A\right)$ of each daughter branch was computed next:

$$
G_{i n}=\frac{\pi \times \mathrm{d}^{3 / 2}}{2 \sqrt{ }\left(R_{m} \times R_{i}\right)} \times\left[\frac{\mathrm{B}+\tanh (\mathrm{X})}{1+\mathrm{B} \times \tanh (\mathrm{X})}\right]
$$

Tanh is the hyperbolic tangent function. For each segment, the voltage transfer from the input $\left(V_{i n}\right)$ to the termination $\left(V_{t}\right)$ was also calculated:

$$
V_{t} / V_{i n}=1 /[\cosh (\mathrm{X})+\mathrm{B} \times \sinh (\mathrm{X})]
$$

where sinh and cosh are the hyperbolic sine and cosine functions, respectively ( $\tanh =\sinh / \cosh$ ). This equation computed the percentage of the input voltage remaining at the end of the cable segment. Thus, electrical transfer as used here is the inverse of attenuation.

The input conductances $\left(G_{\text {in }}\right.$ or $\left.Y_{\text {in }}\right)$ of the daughter branches at each junction were summed. This value formed the new terminating conductance $\left(G_{t}\right.$ or $Y_{t}$, as in Fig. $1 A$ ) of the parent segment. Proceeding proximally, an input conductance was calculated for each major dendritic trunk (as in Fig. 1B). These conductances were added to that of the soma, forming the total calculated neuron input conductance, $G_{N}$. The initial assumption for $R_{m}$ was progressively altered until the calculated $R_{N}$ value $\left(1 / G_{N}\right)$ matched the physiologically measured $R_{N}$ for that cell. This unique $R_{m}$ value for that cell was then used in the further calculations.

This format of calculations reconstructed the somatic response in the model to simulated current inputs. An overall voltage transfer to dendritic sites could also be computed for somatic voltage injection. This value was termed retrograde voltage transfer $\left(V_{r}\right)\left(K_{12}\right.$ as described by Carnevale and Johnston, 1982).

Dendritic inputs. Electrical transfer to the soma was also computed for simulated dendritic shaft and spine inputs (applied to the right in Fig. 1B). The same calculations as above were followed, using equations 1,2 , and 3, but in an inverted order (also schematicized in Turner and Schwartzkroin, 1980). These calculations defined the input resistance of a dendritic branch $\left(R_{d}\right)$ or spine $\left(R_{s p}\right)$. The loading effect of side branches, the soma, and other dendrites was included in these calculations. A typical example is provided in Table II. The overall voltage transfer from a dendritic site to the soma was computed one segment at a time, for a simulated dendritic voltage injection. This parameter was termed orthograde voltage transfer $\left(V_{o}\right)\left(K_{21}\right.$ as described by Carnevale and Johnston, 1982). Typical values are demonstrated in Table II.

Charge transfer $\left(C_{t}\right)$ from a dendritic spine to the soma was also calculated. This estimate was based on the charge effectiveness factor of Barrett and Crill (1974b) (Rinzel and Rall, 1974; Carnevale and Johnston, 1982). A steady input current was simulated at a dendritic site, resulting in a tonic voltage. The transfer to the soma of this steady voltage was calculated. This indirect potential at the soma was compared (as a ratio) with the voltage resulting from the same steady current applied directly to the soma:

$$
C_{t}=\left[R_{d} \times V_{o}\right] / R_{N}
$$

The identical current input to both somatic (denominator) and dendritic (numerator) sites cancelled in the equation.

Rall and Rinzel (1973) have derived a description of orthograde voltage transfer for single inputs onto an equivalent cylinder (E-C) of total electrotonic length $\mathrm{L}$ 
(Fig. 1C):

$$
V_{o}(\mathrm{E}-\mathrm{C})=\left[\frac{\mathrm{R}_{N}}{\mathrm{R}_{d} \times \cosh (\mathrm{L})}\right]
$$

One can also derive the expression for charge transfer to the soma for a single dendritic input to an equivalent cylinder (Rinzel and Rall, 1974). Thus, equation 5 is substituted in equation 4 , resulting in:

$$
C_{t}(\mathrm{E}-\mathrm{C})=1 /[\cosh (\mathrm{L})]
$$

Equation 6 also defines retrograde voltage transfer (from the soma to dendrites), for the E-C model. This can be derived from equation 3 , assuming $\mathrm{B}=0$ (see also Carnevale and Johnston, 1982).

The computer programs were tested by evaluating both unbranched cylinders and branched structures. For these structures, analytically defined electrotonic parameters were compared to the calculated numerical estimates. Additionally, several equivalent cylinder models with extensive branching (Rall and Rinzel, 1973) were tested with the present programs. The specific example tested possessed $M=6$, a terminating diameter of $0.20 \mu \mathrm{m}$, an $R_{N}$ of 29.8 megohms, and $\mathrm{L}=1.0$ length constant.

Dendritic spines. Only the small dendritic spines were included in the present steady-state analysis (Westrum and Blackstad, 1962). Since data on the distribution and intricate structure of the mossy fiber endings on the CA3 pyramidal cells (Amaral and Dent, 1981; Minkwitz, 1976a) is sparse, these were excluded. Because of their small number, though, this loss of area and conductance may not significantly affect the calculated membrane parameters.

The dimensions of spines on CA1 and granule cell dendrites were taken from electron microscopic (EM) studies. For CA1 pyramidal cells spines were assumed to possess the average measurements reported by Westrum and Blackstad (1962), from their EM serial reconstructions (illustrated schematically in Fig. $2 A$ ). Typical measurements were $0.1 \mu \mathrm{m}$ for the spine neck diameter, $0.40 \mu \mathrm{m}$ for the spine stalk strength (to the base of the spine head) and $0.40 \mu \mathrm{m}^{2}$ for the spine head surface area. Variations in dendritic spine shape and dimensions within the CA1 region (see Wenzel et al., 1973) have not been adequately characterized. Hence, these average values were taken to be representative for all CA1 cortical layers. Similar neck dimensions have also been reported in an EM study of the rat CA1 dendritic region by Lee et al. (1980).

Fifkova and Anderson (1981) and Fifkova and Van Harreveld (1977) have measured spine neck widths and spine head areas in an EM study of the dentate region. The minimum spine neck width proved to be $0.10 \mu \mathrm{m}$, although most spines were larger, averaging $0.13 \mu \mathrm{m}$ in the control tissue. However, quantitative data describing variations of spine dimensions throughout the dentate molecular layer were not available. Thus, the average spine dimensions portrayed in Figure $2 A$ were also used in the calculations for the dentate neurons. These values portray the absolute minimum spine neck diameter reported. These values are also similar to EM spine reconstructions measured by Wilson et al. (1983).

There were no available EM measurements of the distal, small spines of CA3 pyramidal cells. Thus, CA3 neurons densely stained with HRP were also subjected to EM examination (two cells). Small spines were measured in both the apical (100 to $350 \mu \mathrm{m}$ from the pyramidal
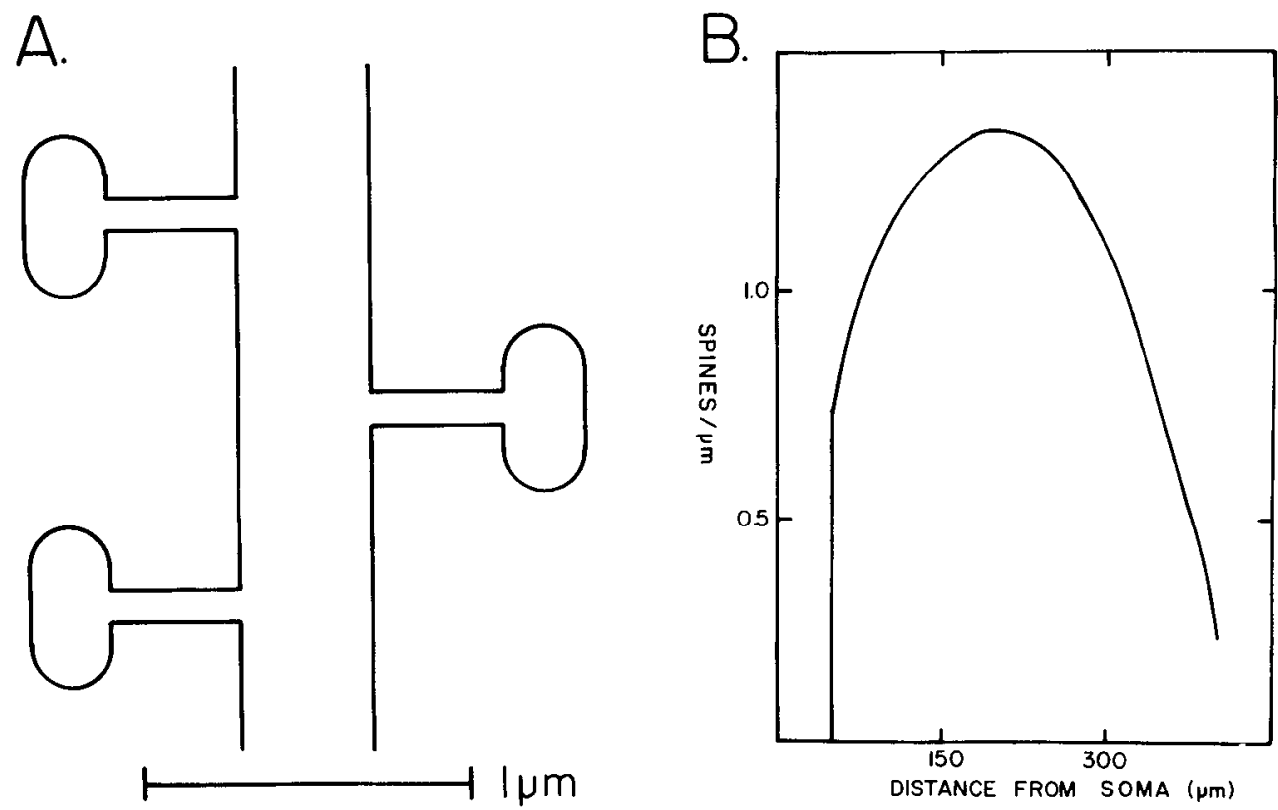

Figure 2. A, A schematic representation of dendritic spines in the models of both CA1 pyramidal and dentate granule cells. The average dimensions were: spine neck width of $0.1 \mu \mathrm{m}$, neck length of $0.4 \mu \mathrm{m}$, and spherical surface area of the spine head of $0.40 \mu \mathrm{m}^{2}$. The CA3 dimensions employed in the calculations were slightly larger (see the text). $B$, The spine density distribution reported by Minkwitz (1976b). This distribution was used in the cable calculations. 
cell layer) and basilar (40 to $200 \mu \mathrm{m}$ from the pyramidal cell layer) dendritic regions (D. Kunkel, D. A. Turner, and L. E. Westrum, unpublished observations). This technique of EM examination of HRP-stained cells has the advantage of considerably enhancing the appearance of the spines (see also Wilson et al., 1983). No systematic variation was noted for spine dimensions in relation to either distance from the pyramidal cell layer or apical versus basilar dendritic regions. There was, however, considerable nonuniformity, even between adjacent or nearby spines. Because of this pleomorphism it was difficult to assign "typical" spine shapes. The dimensions of 105 spines averaged: neck width (as in Fig. 2A), 0.22 $\pm 0.01 \mu \mathrm{m}$; spine neck length, $0.42 \pm 0.02 \mu \mathrm{m}$; and spine head surface area, $0.72 \pm 0.02 \mu \mathrm{m}^{2}$. These averaged measurements were subsequently employed in the calculation on the CA3 pyramidal cells. Although there was shrinkage associated with the EM analysis, this was difficult to quantify and somewhat varible. Thus, no correction factors for EM shrinkage were included.

The spine density distribution of Figure $2 B$ portrays reported measurements from Golgi studies of rat CA1 pyramidal cell apical dendrites (Wenzel et al., 1973; Englisch et al., 1974; Frimmel et al., 1975; Minkwitz, 1976b). In these studies, the density of spines along dendritic branches of the apical dendritic tree was measured as a function of distance from the soma. A generally parabolic distribution was found. This distribution may represent an underestimation of the total number of spines (see Feldman and Peters, 1979). However, these studies present the best available data for hippocampal neurons. Such detailed measurements were not available for the CA3 region. Thus, this distribution was also employed in the CA3 neuron calculations. A similar but more compact distribution was tailored after a Golgi study of the dentate region (Wenzel et al., 1981) for use in that region. The geometric distance between spines in the model (Fig. $2 A$ ) was varied inversely to the density distribution of Figure $2 B$.

The length of dendritic shaft between spines was treated as a short cable segment. Each junction between spine and shaft was considered explicitly. At every junction, the input conductance of both the distal dendritic segment and the spine was added. Thus, the loading conductance of every spine was included in the calculations in a spatially distributed manner. There were additional assumptions required in the cable model to include spines:

1. The dendritic spines were assumed to be uniform and adequately represented by the average dimensions given above.

2. Spines were assumed to be situated according to the parabolic distribution measured for CA1 pyramidal cell dendrites.

3. The dendritic spine head, like the soma, was assumed to be an isopotential region.

\section{Results}

Physiological observations. There were 62 adequate penetrations and attempts at HRP iontophoresis in 18 experiments. Of 29 densely stained cells, 8 of 14 dentate injections demonstrated multiple cell staining, as did 6 of 15 CA3 injections. These multiple neuron stains were discarded. Thus, 6 dentate granule and $9 \mathrm{CA} 3$ pyramidal cells yielded both adequate physiological analyses and dendritic reconstructions. Figure $3 A$ demonstrates the neuronal response of a CA3 pyramidal cell to a $0.5 \mathrm{nA}$ hyperpolarizing pulse. Figure $3 B$ shows the calculation of the longest time constant $\left(\tau_{o}\right)$ on semilogarithmic coordinates. Figure $3 C$ illustrates a typical current-voltage plot and computation of the neuronal inpul resistance $\left(R_{N}\right)$.

Table I presents $R_{N}$ and time constant values for all three major classes of hippocampal neurons (CA1 pyramidal cells from Turner and Schwartzkroin, 1980). Granule cell $R_{N}$ averaged $47.3 \pm 4.6$ megohms (SEM) and CA3 pyramidal cell $R_{N}$ averaged $33.0 \pm 3.0$ megohms. The longest time constant ranged from $9.7 \pm 0.9 \mathrm{msec}$ for the dentate granule cells to $22.7 \pm 1.6 \mathrm{msec}$ for the CA3
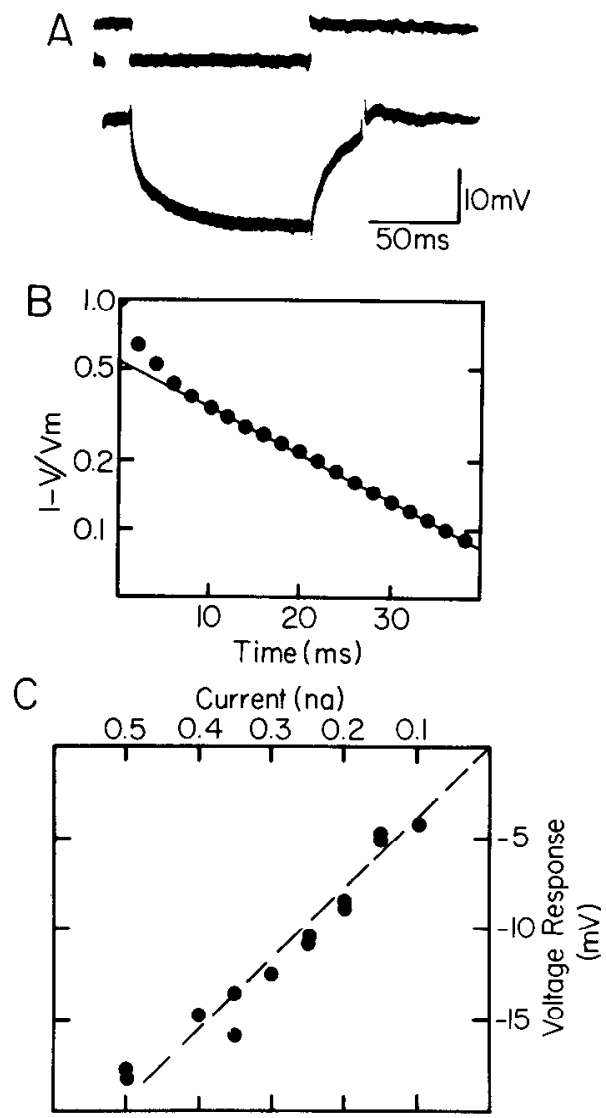

Figure 3. A, An intracellular injection of a $0.5 \mathrm{nA}$ current pulse (hyperpolarizing) into a CA3 pyramidal cell and the resulting voltage response. The upper trace is the current monitor. $B$, The charging voltage response $(V)$ to the current pulse in $A$ was plotted on semilogarithmic coordinates $\left(\log _{10}\right)$. First, the response was normalized with respect to the maximum response $\left(V_{m}\right)$ and then subtracted from one $\left(1-V / V_{m}\right)$ and plotted versus time. Note the early deviation upward and the later linear portion. The terminal linear points were fitted with a least squares exponential regression. The longest time constant $\left(\tau_{0}\right)$ was found to be $20.9 \mathrm{msec}(r=0.99)$. $C$, A plot of the cell's voltage responses to hyperpolarizing pulses. The points were fitted with a least squares linear regression analysis. The neuron input resistance was 39 megohms $(r=0.98)$. 
TABLE I

Anatomical and electrical neuron parameters ${ }^{a}$

\begin{tabular}{|c|c|c|c|c|c|c|c|c|c|c|c|c|}
\hline \multirow{3}{*}{$\begin{array}{l}\text { Hippocampal } \\
\text { Cell Type }\end{array}$} & \multirow{3}{*}{$\begin{array}{c}R_{N}^{b} \\
\text { (megohms) }\end{array}$} & \multirow{3}{*}{$\begin{array}{c}\tau_{0} \\
\text { (msec) }\end{array}$} & \multirow{3}{*}{$\begin{array}{c}\text { Total } \\
\text { Dendritic } \\
\text { Length } \\
\left(10^{3} \mu \mathrm{m}\right)\end{array}$} & \multirow{3}{*}{$\begin{array}{c}\text { Total } \\
\text { Cell } \\
\text { Area }^{c} \\
\left(10^{3} \mu \mathrm{m}^{2}\right)\end{array}$} & \multirow{3}{*}{$\begin{array}{c}\text { No. of } \\
\text { Spines } \\
\left(10^{3}\right)\end{array}$} & \multirow{3}{*}{$\begin{array}{c}\text { Spine } \\
\text { Density/ } / \mu \mathrm{m} \\
\text { of Dendrite }\end{array}$} & \multicolumn{2}{|c|}{$\begin{array}{c}\text { Membrane Resistivity } \\
\left(10^{3} \mathrm{ohm}-\mathrm{cm}^{2}\right)\end{array}$} & \multicolumn{4}{|c|}{ Electronic Length (Length Constants) } \\
\hline & & & & & & & \multirow{2}{*}{$\mathrm{B}=0$} & \multirow{2}{*}{$B=1$} & \multicolumn{2}{|c|}{ Apical } & \multicolumn{2}{|c|}{ Basilar } \\
\hline & & & & & & & & & Median & $\operatorname{Max}$ & Median & Max \\
\hline Dentate & 47.3 & 9.7 & 3.7 & 7.9 & 3.1 & 0.84 & 2.35 & 3.12 & 1.12 & 1.65 & & \\
\hline Granule & 4.6 & 0.9 & 0.3 & 0.8 & 0.3 & 0.04 & 0.21 & 0.34 & 0.12 & 0.16 & & \\
\hline \multicolumn{13}{|l|}{$\begin{array}{l}\text { Neuron } \\
\qquad(n=6)\end{array}$} \\
\hline CA1 & 28.2 & 14.0 & 8.4 & 13.1 & 5.3 & 0.61 & 3.12 & 6.03 & 0.78 & 1.49 & 0.54 & 1.23 \\
\hline $\begin{array}{l}\text { Pyramid }^{e} \\
\quad(n=6)\end{array}$ & 3.4 & 1.8 & 0.9 & 1.8 & 0.9 & 0.03 & 0.43 & 1.07 & 0.05 & 0.16 & 0.02 & 0.19 \\
\hline CA3 & 33.0 & 22.7 & 11.5 & 29.3 & 7.5 & 0.66 & 7.89 & 14.75 & 0.69 & 1.29 & 0.32 & 0.75 \\
\hline $\begin{array}{l}\text { Pyramid } \\
\qquad(n=9)\end{array}$ & 3.0 & 1.6 & 1.2 & 3.5 & 0.9 & 0.04 & 0.59 & 1.55 & 0.08 & 0.10 & 0.02 & 0.12 \\
\hline F ratio $f$ & 6.8 & 6.1 & 14.4 & 17.3 & 8.1 & 8.4 & 38.7 & 23.7 & 9.0 & 1.8 & 53.6 & 5.2 \\
\hline$p$ value & $<0.01$ & $<0.01$ & $<0.001$ & $<0.001$ & $<0.01$ & $<0.01$ & $<0.001$ & $<0.001$ & $<0.01$ & NS & $<0.001$ & $<0.005$ \\
\hline
\end{tabular}

${ }^{a}$ Values are mean \pm SEM.

${ }^{b}$ The measured neuronal input resistance at the soma, $R_{N}$.

"These area estimates include spines, as defined under "Materials and Methods."

${ }^{d} \mathrm{~B}=0$ represents a "sealed-end" termination and $\mathrm{B}=1$ represents an "infinite cable" termination, as defined in the text.

'The CA1 cells are a subpopulation of those reported previously (Turner and Schwartzkroin, 1980).

'The null hypothesis for the one-way analysis of variance assumed the means were identical (2,18 degrees of freedom). The $p$ value indicates the significance at which this hypothesis can be rejected. NS indicates nonsignificant.

pyramidal cells. Both $R_{N}$ and $\tau_{o}$ values were similar to previous reports (Barnes and McNaughton, 1980; Brown et al., 1981a; Johnston, 1981; Wong and Prince, 1981; Durand et al., 1983).

Anatomical observations. Figures 4 and 5 are photomicrographs of a dentate granule cell and a CA3 pyramidal neuron, respectively, after being injected with HRP. The dendritic trees of the granule cells were densely covered by small dendritic spines (Fig. 4). The CA3 cells exhibited large "excresences" (Lorente de No, 1934; Amaral and Dent, 1981) on the proximal apical dendrites and small spines throughout the more distal dendritic tree (Fig. 5).

Figure 6 shows two camera lucida drawings of HRPfilled neurons. The dendrities of the granule cell coursed toward the hippocampal fissure (Fig. $6 A$, near the top). The fine axon emanating from the inferior surface of the soma could be followed into the CA4 region. Figure $6 B$ illustrates a CA3 pyramidal cell, which exhibited a paucity of dendritic side branches on the proximal apical tree. The HRP-stained neurons were contained mainly within one $75-\mu \mathrm{m}$ section. Usually, some smaller dendritic branches were located on adjacent sections. This finding is consistent with earlier observations on CA1 cells (Turner and Schwartzkroin, 1980). The "flatness" of these cells may correspond to selection of neurons that lie within the plane of the "in vitro" hippocampal slice. Both the dendritic morphology and variability were similar to previous Golgi descriptions of hippocampal neurons (Lorente de No, 1934; Lindsay and Scheibel, 1976; Minkwitz, 1976a; Wenzel et al., 1981).

Table I presents anatomical parameters of these neurons. The neurons are listed in rank order of total cell area. The dentate granule neurons were the smallest, measuring $7.9 \pm 0.8 \times 10^{3} \mu \mathrm{m}^{2}$. The CA3 pyramidal cells were the largest and averaged $29.3 \pm 3.5 \times 10^{3} \mu \mathrm{m}^{2}$. These measurements confirm the visual impression (Lor-

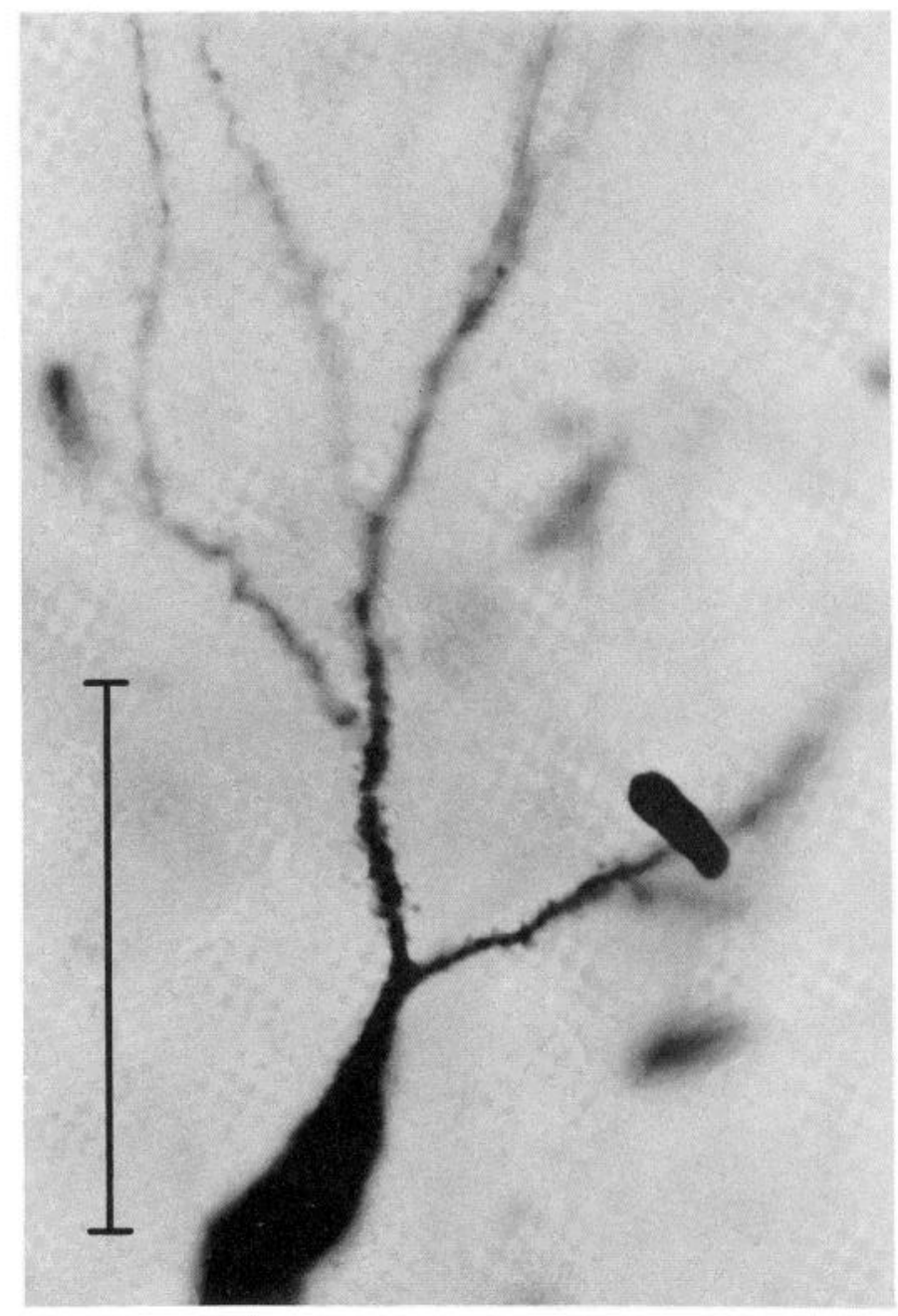

Figure 4. Photomicrograph of an HRP-injected dentate granule cell, with hippocampal fissure above and dentate hilus below. The scale bar represents $50 \mu \mathrm{m}$. Note the dense small spines. 
ente de No, 1934) that the CA3 neurons are large compared to the CA1 pyramidal cells. Morphometric measurements of CA1 pyramidal cells based on rat Golgi preparations yielded a value for average total dendritic length of $5.6 \times 10^{3} \mu \mathrm{m}$ (Minkwitz, 1976b), compared to $8.4 \times 10^{3} \mu \mathrm{m}$ for the present HRP-stained CA1 pyramids. Correcting both estimates for shrinkage (approximately $15 \%$ linear shrinkage for Golgi, Mannen, 1966) gives revised estimates of $6.6 \times 10^{3} \mu \mathrm{m}$ for the Golgi cells and $8.75 \times 10^{3} \mu \mathrm{m}$ for the HRP cells. Thus, the HRP-derived total dendritic length appears to be comparable to Golgi measurements. Granule cells in the dentate gyrus of rats (Golgi analysis) were found to have a total dendritic extent of approximately $450 \mu \mathrm{m}$ (Frimmel et al., 1975). This figure is considerably less than the total dendritic extent of the HRP-stained granule cells, $3.7 \times 10^{3} \mu \mathrm{m}$ (see also Durand et al., 1983).

Dendritic branching. The dendritic branching assumptions of the equivalent cylinder (E-C) model (Rall, 1959, 1977) were assessed. One implication of the E-C model is that the branch point ratio should equal one. This ratio compares the sum of the daughter branch diameters, each raised to the three-halves power, to the parent dendritic diameter (also raised to the three-halves power). For 3179 branch points the ratio of diameters

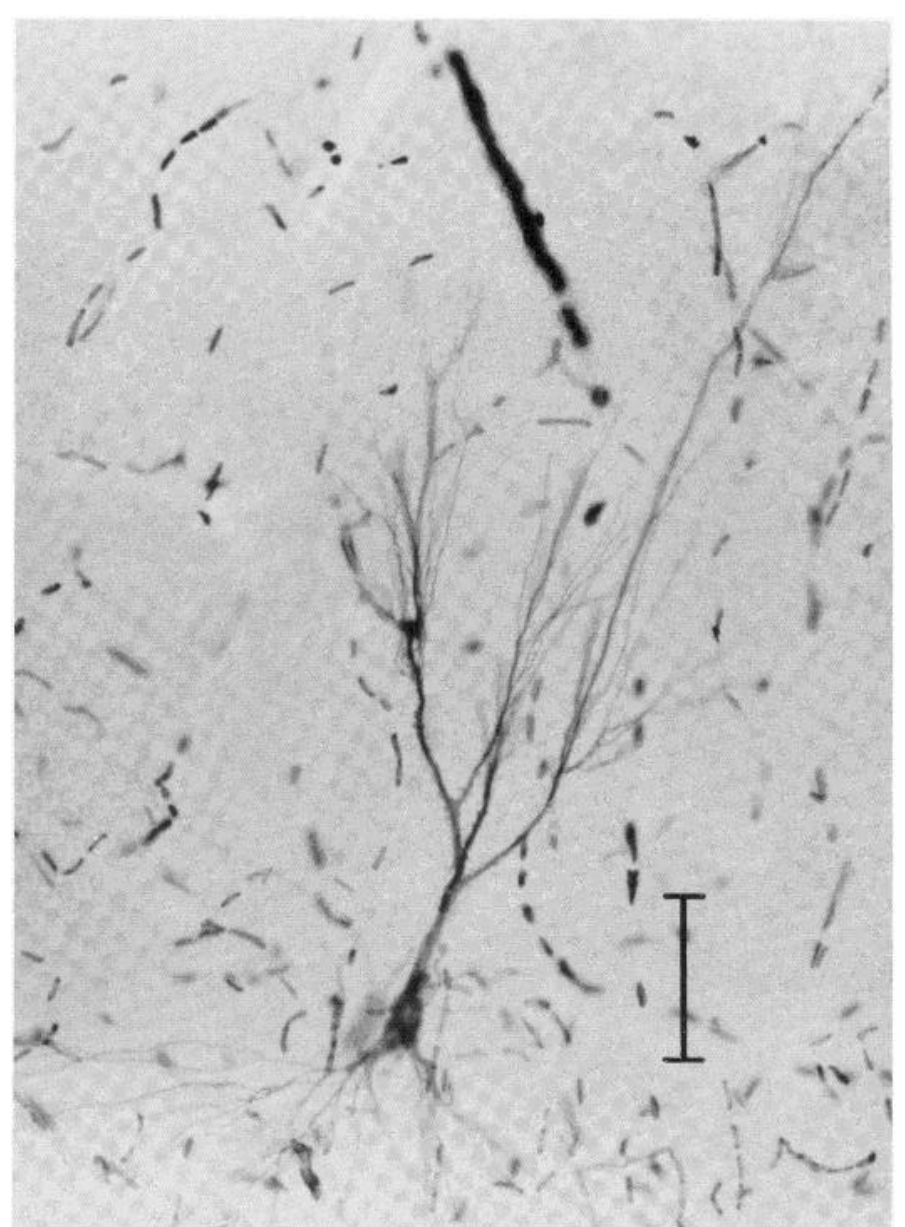

Figure 5. A photomicrograph of an HRP-injected CA3 pyramidal cell. The hippocampal fissure is oriented upward and the fimbria is below. Note the initial branchless region of the apical dendrite, in the stratum lucidum. The scale bar represents $100 \mu \mathrm{m}$. averaged $0.95 \pm 0.01$. Thus, this corollary of the E-C model was approximately satisfied for all cell types.

Adherence to the E-C model also requires that the dendritic trunk parameter remain constant to the point of termination. The dendritic trunk parameter is a description of the sum of dendritic diameters, as a function of electrotonic distance from the soma. Each diameter is first raised to the three-halves power. Figure 7 plots this trunk parameter for representative dentate (Fig. $7 \mathrm{~A}$ ) and CA3 (Fig. $7 B$ ) cells. The overall trunk parameter decreased rapidly in the CA3 pyramidal neurons. This approximately exponential falloff is similar to Sholl's (1953) estimates of dendritic loss (versus geometric distance) in neocortical pyramidal cells. The decrease in both cases appeared due to the large number of short terminations. These are depicted in the upper graph of Figure $7 B$. Short terminating segments were less noticeable in the dentate granule cells (Fig. $7 A$ ). Thus, the dentate granule neurons approximately fulfilled the E-C model. However, the CA3 pyramidal neurons could not be adequately approximated by a single equivalent cylinder and soma.

Specific membrane resistivity. Specific membrane resistivity values $\left(R_{m}\right)$ were computed, assuming $R_{i}=75$ ohm-cm and either $\mathrm{B}=0$ or $\mathrm{B}=1$ (Table I). This parameter ranged from values of 2,350 and $3,120 \mathrm{ohm}$ $\mathrm{cm}^{2}(\mathrm{~B}=0$ and $\mathrm{B}=1)$ for the dentate granule cells to 7,890 and $14,750 \mathrm{ohm}-\mathrm{cm}^{2}$ for the CA3 pyramids. The total number of spines included in the model of each cell varied. This number averaged $3.1 \pm 0.3 \times 10^{3}$ for the dentate granule cells and $7.5 \pm 0.9 \times 10^{3}$ for the CA3 pyramidal cells (Table I). For Golgi-stained CA1 pyramids, the total cell average of spines per micrometer of dendritic length has been estimated to be approximately 0.55 to 0.61 (Wenzel et al., 1973; Englisch et al., 1974; Minkwitz, 1976b). Overall spine density for these HRPstained CA1 cells averaged 0.61 . The values of $R_{m}$ that satisfied the observed $R_{N}$ in the calculations were found to be about 15 to $25 \%$ higher when spines were included in the calculation than when spines were omitted. The wide range of $R_{m}$ noted in Table I parallels the differences in cell area of the three cell types.

Electrotonic length. The median electrotonic distance from the soma to individual dendritic terminations is also presented in Table I. The basilar and apical dendritic trees are shown separately. The median ranged between 0.69 (CA3 apical dendrite) and 1.12 (dentate granule neuron) length constants. This small value indicates that the hippocampal neurons are electrically compact. The median values are consistent with those derived physiologically in similar hippocampal cells (Brown et al., 1981a; Johnston, 1981; Durand et al., 1983). However, as noted in Figure 7, these cells also demonstrated a wide spread of terminations around these median values.

Soma voltage injection. The distribution of steady-state voltage to dendritic sites after simulated soma injection was calculated. Figure 8 presents this factor, for a variety of dendritic locations. The value is termed retrograde voltage transfer, and indicates the predicted dendritic effectiveness of a steady-state voltage clamp at the soma. The solid line in the graphs shows the calculated transfer from the soma to the termination of an equivalent cylinder (equation 6). For most sites, the deviation from the 

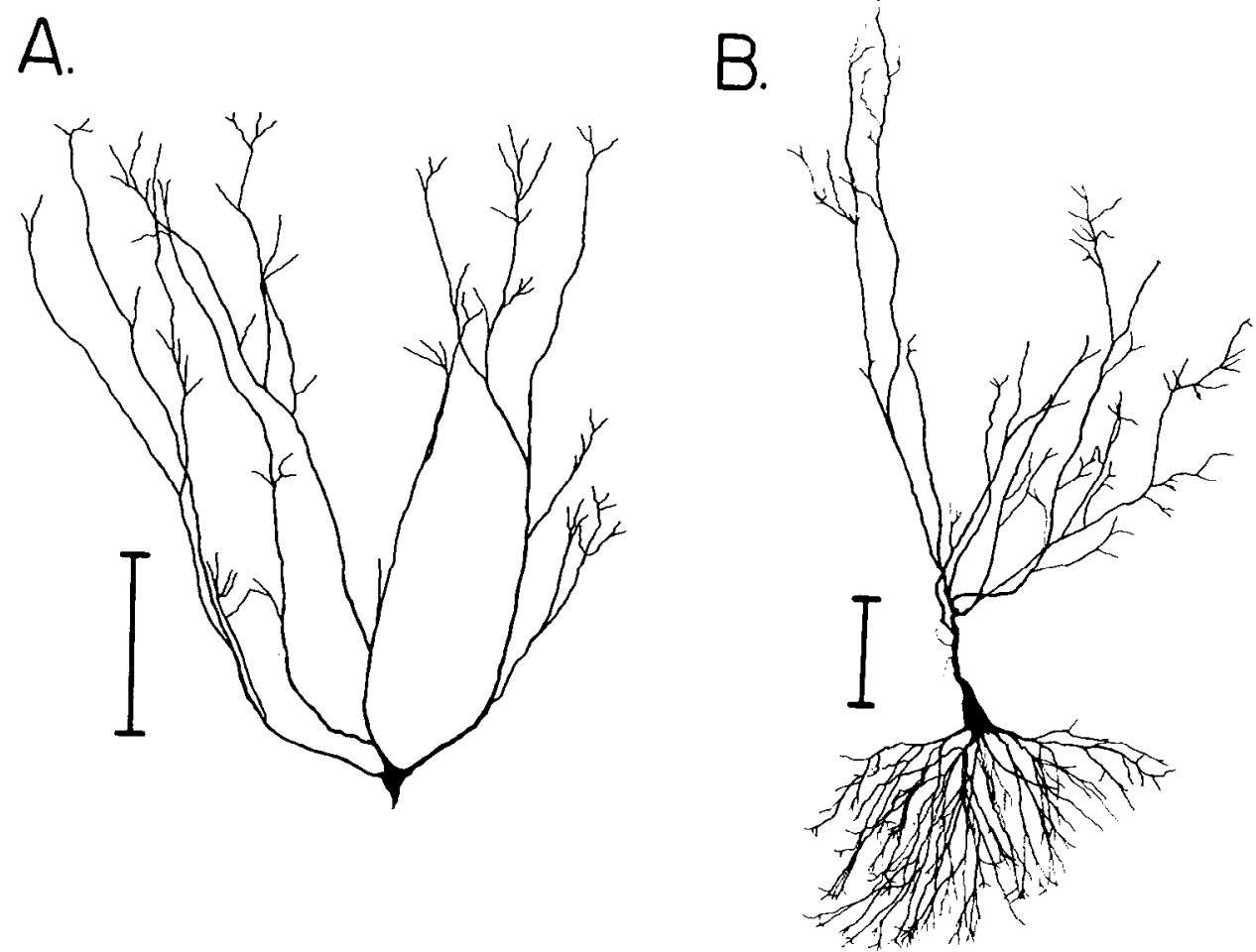

Figure 6. A, A camera lucida reconstruction of a dentate granule cell (scale bar is 100 $\mu \mathrm{m})$. The axon courses downward, into the dentate hilus; the hippocampal fissure lies above. $B$, A camera lucida reconstruction of a typical CA3 pyramidal cell, with the apical dendrite coursing upward towards the hippocampal fissure (scale bar is $100 \mu \mathrm{m}$ ).

E-C prediction (for that electrotonic length) was less than $20 \%$. This deviation was due to local variations from an ideal E-C model (Rall and Rinzel, 1973) in dendritic branching. The percentage transfer of applied soma voltage to proximal portions of the dendritic tree appeared to be relatively high.

Dendritic inputs and resistances. Table II shows a typical calculation of dendritic shaft $\left(R_{d}\right)$ and spine $\left(R_{s p}\right)$ input resistances. These values ranged from approximately $1.5 \times 10^{8} \mathrm{ohms}$ to $8 \times 10^{9} \mathrm{ohms}$, or 3 to 200 times the input resistance at the soma, $R_{N}$. The spine core resistance, $R_{s s}$, was 38 megohms for the dimensions given in Figure $2 A$. As seen in Table II, the spine input resistance, $R_{s p}$, is approximately equal to the sum of $R_{d}+R_{s s}$ (Rall, 1974). However, most spines occur in the middle portion of the dendritic tree (Fig. $2 B$ ), or at distances of greater than $150 \mu \mathrm{m}$ from the soma (Valverde and RuizMarcos, 1969; Wenzel et al., 1973, 1981; Englisch et al., 1974; Minkwitz, 1976b; Meyer and Ferres-Torres, 1978). Thus, only the higher resistance dendritic sites, at further distances from the soma, would tend to possess spines.

The equivalent cylinder cell utilized in the calibration of these calculations possessed a total $\mathrm{L}=1.0, R_{N}=29.8$ megohms, $R_{m}=5000 \mathrm{ohm}-\mathrm{cm}^{2}, \mathrm{M}=6$, and a final dendritic diameter of $0.20 \mu \mathrm{m}$ (see Rall and Rinzel, 1973, for the exact construction of this model neuron). This cell matches closely the parameters and dimensions of the present set of hippocampal neurons. The terminal $R_{d}$ in this neuron is $1.35 \times 10^{9} \mathrm{ohms}$, or 45.3 times $R_{N}$. For slightly different parameters, the ratio of $R_{d} / R_{N}$ may vary up to approximately 200 , as in the examples tabulated in Rall and Rinzel (1973). Thus, the calculated range of the ratio $R_{d} / R_{N}$ in the present neurons is entirely consistent with a detailed theoretical model. However, the $R_{N}$ values are higher than many authors have presumed for cortical pyramidal cells (Rall and Rinzel, 1973; Rall, 1974; Koch and Poggio, 1983).

To gain insight into the variation of $R_{d}$ (and $R_{s p}$ ) values throughout these dendritic trees, sites within geometrical regions of the dentate and CA1 cells were averaged. For the dentate granule cells, these averages were derived for the middle and outer molecular layer regions, where the perforant path terminates (Barnes and McNaughton, 1979, 1980; McNaughton et al., 1981). The middle layer $R_{d}$ values averaged $5.95 \pm 0.49 \times 10^{8} \mathrm{ohms}(n=144$ sites), compared to Rall's (1974) estimate of $1 \times 10^{8}$ ohms. The outer third $R_{d}$ averaged $12.8 \pm 10^{8}$ ohms ( $n=$ 144 sites), compared to Rall's (1974) prediction of $10 \times$ $10^{8} \mathrm{ohms}$. Both of Rall's (1974) calculations were preliminary suggestions based upon the E-C model but appear surprisingly close to the present estimates.

$R_{d}$ values were also derived for proximal and distal regions of the CA1 pyramidal cells, similar to the study of Andersen et al. (1980). These two regions were calculated to possess $R_{d}$ values of $10.6 \pm 0.55 \times 10^{8}$ and 13.3 $\pm 0.9 \times 10^{8} \mathrm{ohms}$, respectively, for $n=144$ sites each. These values are somewhat higher than those for the dentate granule cells, because there are many finer side branches off the CA1 cells in the stratum radiatum (in the range of 0.15 to $0.20 \mu \mathrm{m}$ ). Also, the CA1 cells exhibited longer total dendritic span and higher $R_{m}$ values 
than did the dentate cells (Table I). Both of these factors would tend to increase the $R_{d}$ values.

In both these sets of cells it is apparent that the spine input resistances, $R_{s p}$, are mainly determined by the $R_{d}$ values. The $R_{s s}$ value that is characteristic for both the CA1 and dentate cells, 38 megohms, is substantially lower than the average $R_{d}$ values in either case. This important finding suggests that the influence of the spine stem is less than $10 \%$, on the average, when viewed according to Rall's method of comparing $R_{d}$ with $R_{s s}$.

Another method to test spine signal attenuation involved the direct calculation of voltage transfer to the soma. Inputs to either a spine or the adjacent dendritic shaft were compared, in terms of their effectiveness at the soma (see Table II for an example). Both revealed significant signal attenuation: 0.25 to $5 \%$ of the input voltage signal was transferred to the soma, with only a

A.
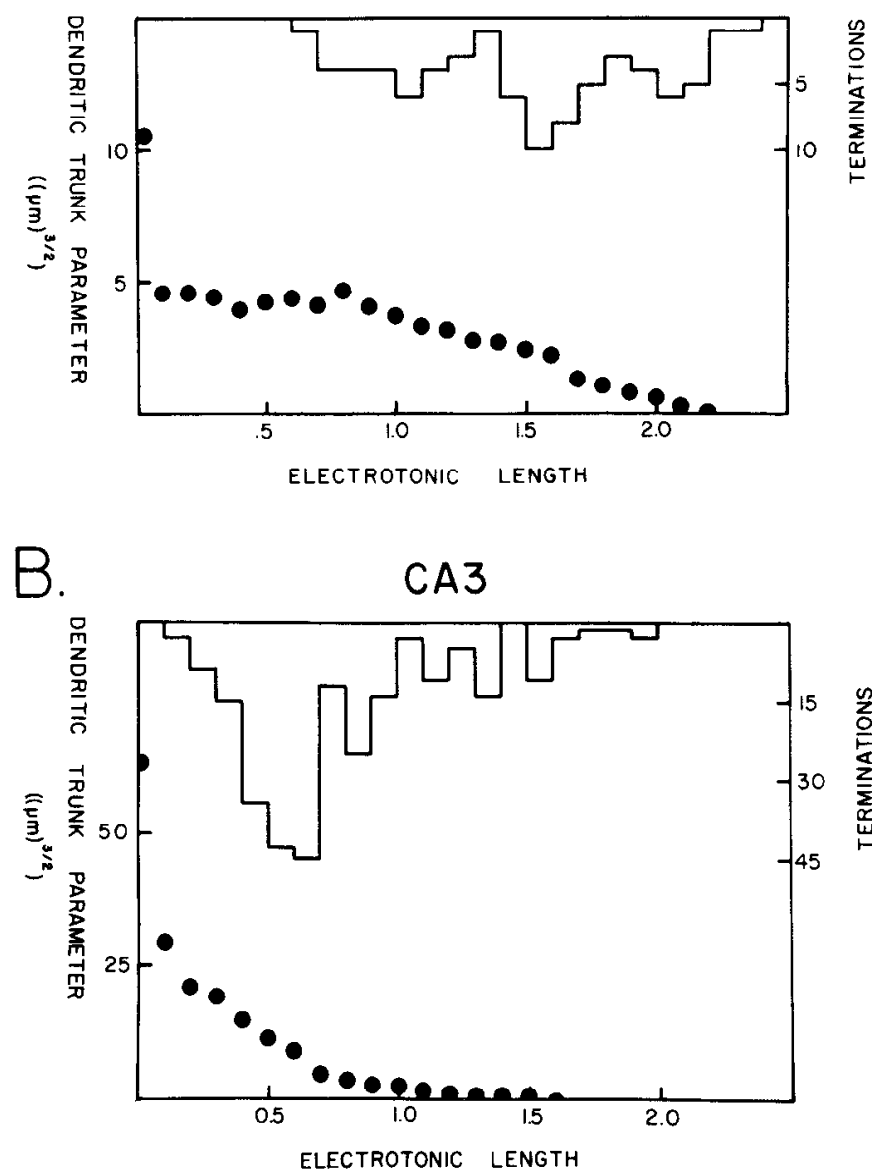

Figure 7. A, A plot of dendritic trunk parameter (left ordinate) versus electrotonic distance from the soma, for a represenative dentate granule cell. The initial rapid taper and subsequent stable level (to about 1.0 length constant) was typical for these cells. The upper graph is a histogram of the terminating distance of individual dendritic segments (right ordinate) versus electrotonic length. $B, \mathrm{~A}$ similar plot for a representative CA3 pyramidal cell. A rapid loss of overall trunk parameter was typical for all of the CA3 pyramids. This loss appeared due to the large number of electrically short terminations (upper graph). The apical and basilar dendritic trees are combined in this illustration.

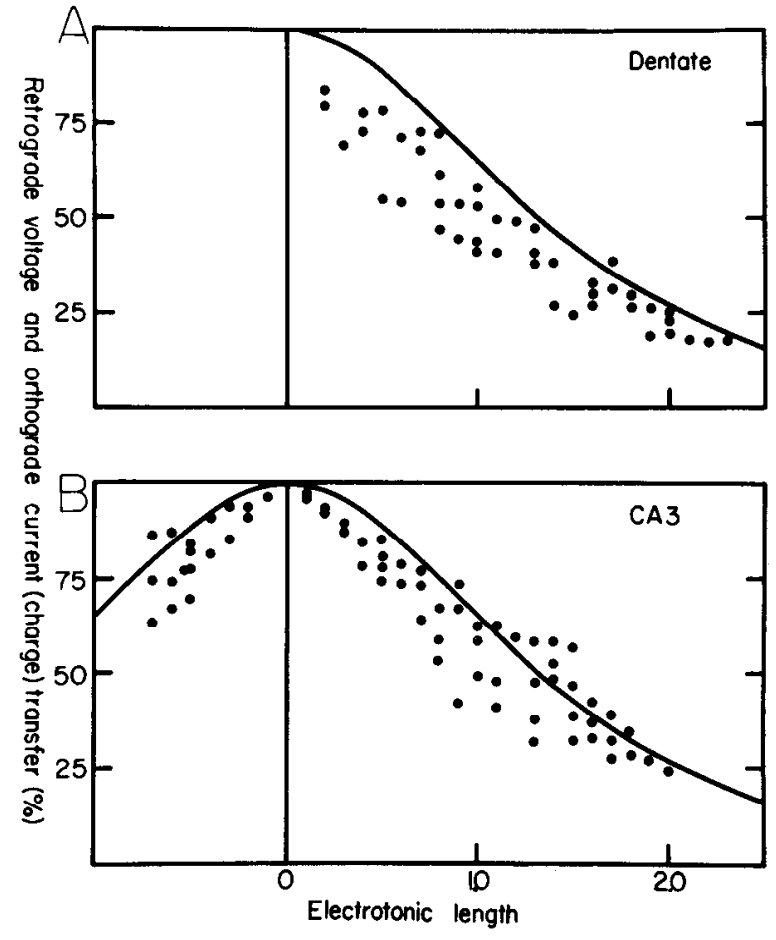

Figure 8. A, Orthodromic charge transfer values (or retrograde voltage transfer) were plotted versus electrotonic distance for a representative dentate granule cell. The solid curve shows the ideal charge transfer to the soma for a single input at the terminus of an equivalent cylinder. The scatter of individual values calculated in the present study indicates the range of transfer values for different sites, which possess the same electrotonic length. $B, A$ similar plot, but for a representative CA3 pyramid. The basilar dendrites are to the le $/ l$ and the apical dendrites are to the right of the vertical line (representing the soma). The vertical spread indicates the variability of values for sites sharing the same electrotonic length, but at different locations.

slight difference noted between spine and shaft inputs. There was an average of greater than $90 \%$ signal transfer across the spine neck, for steady-state voltage. Thus, nearly all of the voltage loss of the transferred signal occurred in passive dendritic conduction, not in spine conduction. A similar result is found when spine and dendritic shaft inputs are compared using the complex E-C model (Rall and Rinzel, 1973), when the neuron parameters are similar.

Another estimate of synaptic efficacy, charge transfer $\left(C_{t}\right)$, can be derived from the integral of either voltage or current waveforms (Edwards et al., 1976; Carnevale and Johnston, 1982). This measure is independent of the timing of an input waveform and hence may be a good predictor of the steady-state efficacy of a dendritic site (Barrett and Crill, 1974b; Rinzel and Rall, 1974). Figure 8 illustrates $C_{t}$ values from various dendritic spines to the soma, versus electrotonic distance (the values are the same as for $V_{r}$ ). The solid curve in Figure 8 shows the ideal charge transfer for the $\mathrm{E}-\mathrm{C}$ model as a function of terminating electrotonic length (equation 6). Each point gives the value calculated for a specific spine input. The dispersion of points stems from the variable dendritic branching. Most of the values lie close to the continuous 
TABLE II

Segmental cable calculation example

\begin{tabular}{|c|c|c|c|c|c|c|c|c|c|c|c|c|c|}
\hline Segment No. & $l^{b}$ & $\Sigma l$ & $d$ & $\mathrm{X}^{\mathrm{c}}$ & $\Sigma \mathrm{x}$ & $G_{i n}{ }^{d}$ & $G_{12}$ & $G_{s p}$ & $R_{d}$ & $R_{s p}$ & $R_{d} / R_{N}$ & $V_{o}^{e}$ & $C t$ \\
\hline & & $\mu m$ & & \multicolumn{2}{|c|}{ length constants } & & $10^{-9} \mathrm{~S}$ & & \multicolumn{2}{|c|}{$10^{8} \mathrm{ohms}$} & & \multicolumn{2}{|c|}{ \% transfer to soma } \\
\hline Soma & & & & 0.00 & 0.00 & 10.6 & 15.7 & & 0.64 & & 1.00 & 100.0 & 100.0 \\
\hline 1 & 5.0 & 5.0 & 2.88 & 0.01 & 0.01 & 10.7 & 15.5 & & 0.65 & & 1.02 & 99.0 & 99.8 \\
\hline 3 & 102.2 & 118.7 & 0.86 & 0.34 & 0.38 & 5.36 & 6.06 & 4.92 & 1.65 & 2.03 & 2.59 & 33.6 & 86.6 \\
\hline 6 & 75.5 & 194.2 & 0.72 & 0.28 & 0.66 & 3.41 & 4.12 & 3.56 & 2.42 & 2.81 & 3.80 & 18.5 & 20.0 \\
\hline 10 & 34.5 & 228.7 & 0.58 & 0.14 & 0.80 & 2.76 & 3.24 & 2.88 & 3.08 & 3.47 & 4.84 & 13.2 & 65.7 \\
\hline 16 & 33.1 & 386.3 & 0.14 & 0.28 & 1.74 & 0.38 & 0.38 & 0.38 & 26.5 & 26.9 & 41.6 & 1.2 & 49.9 \\
\hline
\end{tabular}

Branching Order

$16 \quad 14,\left.\left.\frac{12}{15}\right|_{9} ^{13} \frac{10}{\left.\right|_{5} ^{11}} \frac{6}{\left.\right|_{5}}\right|^{4} 2 \quad 1 \quad$ Soma

\footnotetext{
${ }^{a}$ This example is from the middle dendrite of the dentate granule cell illustrated in Figure $6 A$. The branching order of the segments is presented schematically below the table. The specific membrane parameters are: $R_{m}=3070 \mathrm{ohm}-\mathrm{cm}^{2}, R_{i}=75 \mathrm{ohm}-\mathrm{cm}$, and terminating B $=0$.

${ }^{b} l$ represents the geometric length of each segment, $\Sigma l$ the summed distance from the soma, and $d$ the diameter.

${ }^{c} \mathrm{X}$ is the electrotonic length of each segment and $\Sigma \mathrm{X}$ is the summed distance from the soma.

${ }^{d} G_{i n}$ is the input conductance into the soma, not including the distal branching and parallel pathways. $G_{d}$ is the total input conductance including these factors. $G_{s p}$ is the input conductance into a dendritic spine attached at that site (dimensions as in Fig. $2 A$ ). $R_{d}=1 / G_{d}$ and $R_{s p}=$ $1 / G_{s p}$.

${ }^{e} V_{o}$ is the orthograde, steady-state voltage transfer to the soma.

${ }^{f} C_{t}$ is the orthograde charge transfer from that site to the soma.
}

lines, indicating that the E-C model may provide a reasonable approximation for these charge values. Charge transfer was also very high across the spine neck, averaging greater than $90 \%$. This finding indicates that steady-state dendritic spine inputs are only slightly less efficacious than shaft inputs. The critical factor in determining transfer across the spine neck appeared to be the spine neck width. Unless this dimension was less than $0.05 \mu \mathrm{m}$ or the spine was longer than $1.5 \mu \mathrm{m}$, there was greater than $90 \%$ charge transfer across the spine neck. Neither of these extremes have been reported in measurements of hippocampal spines. Even the larger neocortical spines average only $1.1 \mu \mathrm{m}$ in length (Jacobsen, 1967).

As also illustrated in Figure 8, the value of charge transfer from a spine to the soma is identical to the retrograde voltage effectiveness for that site. This analytical identity has been shown previously for both E-C model neurons (Rinzel and Rall, 1974) and a network model (Carnevale and Johnston, 1982). Both values are relatively predictable if the electrotonic distance of the input site to the soma is known. This finding is in contrast to the orthograde voltage values, which demonstrated little direct relationship to electrotonic length. Thus, depending upon which electrical estimate of synaptic potency that one uses, electrotonic length may or may not provide predictive information (see also Turner and Calvin, 1981).

\section{Discussion}

Physiological and anatomical findings. These hippocampal neurons exhibited physiological characteristics similar to those reported in other studies (Table I). The average $R_{N}$ was slightly lower than for similar neurons impaled with potassium acetate electrodes (Barnes and
McNaughton, 1980; Brown et al., 1981a; Johnston, 1981; Wong and Prince, 1981; Durand et al., 1983). This deviation may be due to either increased electrode trauma (coarser electrodes needed to pass HRP) or selection of a different subgroup of cells. The anatomical appearancc of these HRP-stained neurons resembled closely in shape and extent those described in Golgi studies (Lorente de No, 1934; Lindsay and Scheibel, 1976; Minkwitz, 1976a; Stansfield and Cowan, 1979; Wenzel et al., 1981). Dendritic architecture, spines, and bush-like branching were all comparable in Golgi and HRP experiments. Occasional examples of multiple cell staining were observed after HRP injection, possibly indicating electrode trauma or multiple cell impalement (MacVicar and Dudek, 1980).

To evaluate the completeness of cell filling with intracellular HRP injections, one can only compare similar neurons stained with different techniques, primarily the Golgi technique. Allowing approximately $15 \%$ linear shrinkage for Golgi (Mannen, 1966), HRP-injected and Golgi hippocampal cells appear to possess comparable total dendritic length. Other studies of HRP-injected neurons have suggested more extensive dendritic branching than similar Golgi cells (Deschenes et al., 1979; Durand et al., 1983). This qualitative difference may indicate that either additional neuronal structure is being revealed with HRP, or serial section reconstructions are improved by single neuron staining. Dendritic spines and fine terminal branches in HRP-stained cells, as studied with EM, appeared densely filled (D. Kunkel, D. A. Turner, and L. E. Westrum, unpublished observations). Thus, the present HRP-injected neurons appear to portray neuronal structure at least as well as Golgi methods.

The development of the equivalent cylinder neuron model has considerably enhanced the analysis of neu- 
ronal integration (Rall, 1977). One corollary of this model implies that the ratio of parent and daughter branch diameters (all raised to the three-halves power) equals one. These HRP-stained hippocampal neurons demonstrated approximate adherence to this branch point rule. The average ratio was near 1.0 for more than 3000 branch points. Another corollary of the E-C model is that the dendritic trunk parameter should remain constant to the terminating electrotonic length. None of the HRP-injected pyramidal neurons adhered to this second corollary (Fig. 7B; Turner and Schwartzkroin, 1980). However, the dentate granule cells maintained a relatively constant trunk parameter to 1.0 length constant. Thus, at least as defined by these two indices, the granule neurons appear anatomically close to the ideal "equivalent cylinder neuron."

Calculated parameters. The limitations and assumptions of this steady-state cable model have been discussed previously (Rall, 1959, 1977; Turner and Schwartzkroin, 1980; Turner and Calvin, 1981). The calculated values of $R_{m}$ fell within a range of 1,000 to $20,000 \mathrm{ohm}-\mathrm{cm}^{2}$. This range is consistent with estimates for both vertebrate and invertebrate neurons (Barrett and Crill, 1974a; Brown et al., 1981b; Rall, 1981; Lam and Johnston, 1982). The $R_{m}$ calculated for hippocampal neurons may, of course, underestimate the "true" $R_{m}$ value. Underestimation could result from such considerations as inadequate quantitation of the membrane surface area, nonuniformity of $R_{m}$, exclusion of the extracellular resistance, or an inaccurate estimation of $R_{i}$. Low values for membrane surface area might result from the exclusion of dendritic surface irregularities, underestimation of numbers or size of spines, or disregard for EM shrinkage. The present model excludes the external resistivity $\left(r_{e}\right)$, but this factor may be relatively important in the central nervous system (Rall, 1977). The addition of $r_{e}$ would require a higher $R_{m}$ value, in order to satisfy the cell's measured $R_{N}$. A higher estimate for $R_{i}$ would also force $R_{m}$ upward. Finally, there may be a high rate of ongoing spontaneous synaplic activity in the dendrites or soma; such activity might also lead to an underestimation of the "resting" $R_{m}$.

The methods of this study have included efforts to decrease shrinkage, to perform three-dimensional reconstructions of each neuron, and to include dendritic spines. However, the factors discussed above may continue to be responsible for underestimation of both membrane surface area and $R_{m}$. Thus, the bracketing values of $R_{m}$ presented in this study are initial lower bound estimates for the "real" $R_{m}$ value. It should be noted, too, that electrotonic length decreases and that electrical transfer values increase with higher $R_{m}$. Thus, the present estimates for dendritic effectiveness should also be viewed as lower bound estimates. Additionally, the $R_{d}$ and $R_{s p}$ values are lower bound predictions, because these, too, will increase with a higher $R_{m}$.

Electrotonic distance $(\mathrm{X})$ to an input site is one predictor of that site's electrical efficacy. The present anatomically derived $\mathrm{X}$ values are close to reported physiological total L estimates, which assumed the E-C model. Brown et al. (1981a) derived 0.90 and 0.93 length constants for CA1 and CA3 pyramidal cells, respectively, and 0.94 for granule cells. Durand et al. (1983) computed a range of 0.9 to 1.25 length constants for granule neurons, and Johnston (1981) calculated 0.92 to 0.94 length constants for CA3 pyramids. The present estimates of $\mathrm{X}, R_{m}$, and cell branching characteristics are thus consistent with values computed by different methods. The calculated charge transfer from a dendritic site to the soma was similar to a single E-C input at the same electrotonic distance (using the model of Rall and Rinzel, 1973). Thus, charge transfer was relatively predictable for a site at a known electrotonic length, X. However, orthodromic voltage transfer $\left(V_{o}\right)$ values depended more on branch or spine input resistance $\left(R_{d}\right)$ than on electrotonic distance. For the CA1 pyramidal cells in particular, $R_{d}$ and $V_{o}$ varied as a complicated function of X, similar to the branching E-C model of Rall and Rinzel (1973).

The steady-state efficacy of a single dendritic input may be viewed in terms of either the low orthograde voltage transfer to the soma ( $<5 \%$ of the input remaining at the soma) or the relatively high charge transfer $(>20 \%)$. The transient voltage transfer (comparing waveform peaks) from a dendritic site to the soma may be even lower than the steady-state factor (Rall, 1967; Rinzel and Rall, 1974). Since charge transfer has proven difficult to measure experimentally (Edwards et al., 1976), transient voltage transfer may in fact be a better estimate of synaptic efficacy (Jack et al., 1981). Unfortunately, transient calculations are beyond the reaches of this steady-state report. Likewise, EPSPs are much more appropriately modelled by a transient conductance charge, also beyond the present calculations. However, preliminary calculations (Turner, 1982) suggest that the transient $Z_{d}$ also is significantly greater than $Z_{s s}$. Thus, in either the present steady-state or preliminary transient calculations, the main determinant of spine input impedance is predicted to be $R_{d}$ (however, see Koch and Poggio, 1983). Both steady-state and transient voltage calculations thus suggest spine signal attenuation to be less than $10 \%$.

Dendritic spines. Hypotheses on the role of dendritic spines in the central nervous system are varied. Several theories were assessed with the incorporation of spines in the present steady-state, segmental model.

Diamond et al. (1971) hypothesized that electrical events in the dendritic shaft were isolated from the spine head. These authors also suggested that an input to the spine head should be significantly attenuated in transfer to the dendritic shaft. These hypotheses are not supported by the present data. The spine neck corresponds to a very short dendritic cable, on the order of $4 \times 10^{-3}$ length constants. Such a short cable segment contributed very little attenuation to steady-state signals, in terms of either voltage or charge. Because of this minimal degree of attenuation, there was also no effective isolation of the spine head. This finding was true for shapes and lengths of dendritic spines other than the average spine portrayed in Figure 2A. A decrease of synaptic transfer across the spine to less than $90 \%$ required the spine neck to be greater than $1.5 \mu \mathrm{m}$ long $(0.10 \mu \mathrm{m}$ diameter). Such spine dimensions have not been reported in hippocampus and appear to be far out of the "physiologic" range.

Rall (1974) has also explored the possibility that there is significant voltage altenuation across the spine neck. 
In his theoretical formulation the core resistance of the spine neck $\left(R_{s s}\right)$ is compared to the input resistance of the parent dendritic branch $\left(R_{d}\right)$. If these resistances were similar, a small change in spine neck dimension could modulate the transfer of signals across the spine neck. Using the present spine dimensions (which do not account for shrinkage) and assumed $R_{i}$ values, the spine stem resistance was calculated to be $0.38 \times 10^{8} \mathrm{ohms}$. This low value is in contrast to the average dendritic input resistances of 5 to $13 \times 10^{8} \mathrm{ohms}$ and yields less than $10 \%$ spine attenuation of the input signal. Rall (1974) predicted the ratio of $R_{s s} / R_{d}$ to be in the range of 0.1 to 1 . In the present study this ratio was uniformly near or less than 0.1 , but still within Rall's suggested range (see also Rinzel, 1982).

Because our study did not account for shrinkage produced by EM processing, the dimensions we present most likely underestimate those of "realistic" dendritic spines. Spine neck diameters of less then $0.1 \mu \mathrm{m}$ would be rather unusual (Fifkova and Anderson (1981) measured 0.13 $\mu \mathrm{m}$ ), so that a higher $R_{s s}$ value would be rare. Thus, $R_{s s}$ may be an overestimate of the "true" value. Furthermore, we have possibly underestimated $R_{d}$, based on our lower bound estimate of $R_{m}$. An increased $R_{d}$ or lower $R_{s s}$ values would result in an even higher resistance ratio, $R_{s s} /\left(R_{d}\right.$ $+R_{s s}$ ), making attenuation across the spine neck more unlikely. A higher value for $R_{i}$ could, of course, increase the spine neck resistance, but would also change the $R_{d}$ values in an upward direction.

Thus, considering both spine dimensions measured by EM and the steady-state input resistance calculated with the cable model, the spine attenuation modulation envisioned by Rall (1974), Rinzel (1982), and Koch and Poggio (1983) does not appear to be important in these hippocampal neurons. If some of the cable model assumptions are invalid, however, spines may indeed serve to modulate synaptic transfer. For instance, if $R_{i}$ in the spine neck was different from, and varied independently of, $R_{i}$ in the parent dendrites, changes in spine $R_{i}$ could significantly alter the resistance ratio. Also, transient EPSPs may certainly differ from the present steadystate predictions.

Fifkova and Anderson (1981) and Fifkova and Van Harreveld (1977) have reported that spines on dentate granule cells became markedly swollen after intense stimulation. They observed a $40 \%$ increase in the planar surface area of the spine head after such a barrage. This magnitude of increase in the surface area does not alter substantially any of the spine attenuation factors defined above. Rather, the low spine attenuation is decreased even further. This swelling could, however, be a metabolic response to the intense stimulation.

Other theories regarding an electrical modulation or attenuation role of small dendritic spines are likewise not supported by the present set of data (Crick, 1982; Gray, 1982). These hypotheses, however, may be appropriate for other sets of neurons. Furthermore, there may be isolation of the spine head from the main dendritic shaft, perhaps affecting metabolic or ionic factors if not electrical transfer. Another possible role may be modulation of the time-dependent synaptic conductance change onto the spine head (Turner, 1982; Koch and Poggio, 1983). Such a modulation might broaden the synaptic event that is transferred to the soma (Andersen et al., 1980). Other possible spine functions include involvement in structural or developmental factors (Purpura, 1974; Swindale, 1981). Spines may also serve to increase the surface area of attachment of a synapse to the postsynaptic cell (Amaral and Dent, 1981). Most synaptic inputs onto hippocampal neurons involve dendritic spines. Their role in neuronal synaptic integration may be substantial but is, as yet, undefined.

\section{References}

Amaral, D. G., and J. A. Dent (1981) Development of the mossy fibers of the dentate gyrus. I. A light and electron microscopic study of the mossy fibers and their expansions. J. Comp. Neurol. 195: 51-86.

Andersen, P., H. Silfvenius, F. H. Sundberg, and O. Sveen (1980) A comparison of distal and proximal dendritic synapses on CA1 pyramids in guinea pig hippocampal slices in vitro. J. Physiol. (Lond.) 307: 273-299.

Barnes, C. A., and B. L. McNaughton (1979) Neurophysiological comparison of dendritic cable properties in adolescent, middle-aged and senescent rats. Exp. Aging Res. 5: 195-206.

Barnes, C. A., and B. L. McNaughton (1980) Physiological compensation for loss of afferent synapses in rat hippocampal granule cells during senescence. J. Physiol. (Lond.) 309: 473-485.

Barrett, J. N., and W. E. Crill (1974a) Specific membrane properties of cat motoneurons. J. Physiol. (Lond.) 239: 301324.

Barrett, J. N., and W. E. Crill (1974b) Influence of dendritic location and membrane properties of the effectiveness of synapses on cat motoneurons. J. Physiol. (Lond.) 239: 325345.

Brown, T. H., R. A. Fricke, and D. H. Perkel (1981a) Passive electrical constants in three classes of hippocampal neurons. J. Neurophysiol. 46: 812-827.

Brown, T. H., D. H. Perkel, J. C. Norris, and J. H. Peacock (1981b) Electrotonic structure and specific membrane properties of mouse dorsal root ganglion neurons. J. Neurophysiol. 45: $1-15$.

Carnevale, N. T., and D. Johnston (1982) Electrophysiological characterization of remote chemical synapses. J. Neurophysiol. 47: 606-621.

Crick, F. (1982) Do dendritic spines twitch? Trends Neurosci. 5: $44-46$.

Deschenes, M., A. LaBelle, and P. Landry (1979) Morphological characterization of slow and fast pyramidal tract cells in the cat. Brain Res. 178: 251-274.

Diamond, J., E. G. Gray, and G. M. Yasargil (1971) The function of the dendritic spine: An hypothesis. In Excitatory Synaptic Mechanisms, P. Andersen and J. K. S. Jansen, eds. pp. 213-222, Universitetsforlaget, Oslo.

Durand, D., P. L. Carlen, N. Gurevich, A. Ho, and H. Kunov (1983) Electrotonic parameters of rat dentate granule cells measured using short current pulses and HRP staining. J. Neurophysiol., in press.

Edwards, F. R., S. J. Redman, and B. Walmsly (1976) Statistical fluctuations in charge transfer in Ia synapses on spinal motoneurons. J. Physiol. (Lond.) 259: 665-688.

Englisch, H. J., G. Kung, and J. Wenzel (1974) Zur Spines Verteilung an Pyramiden-Neuronen der CAl-Region des Hippocampus der Ratte. Z. Mikrosk. Anat. Forsch. (Leipz.) 88: 85-102.

Feldman, M. L., and A. Peters (1979) A technique for estimat- 
ing total spine numbers on Golgi-impregnated dendrites. J. Comp. Neurol. 118: 527-542.

Fifkova, E., and C. L. Anderson (1981) Stimulation-induced changes in dimensions of stalks of dendritic spines in the dentate molecular layer. Exp. Neurol. 74: 621-627.

Fifkova, E., and A. Van Harreveld (1977) Long-lasting morphological changes in dendritic spines of dentate granular cells following stimulation of the entorhinal area. J. Neurocytol. 6: 211-230.

Frimmel, G., H. M. Ost, and J. Wenzel (1975) Quantitative Untersuchungen zur Neuronstruktur des Fascia Dentata der Ratte. Z. Mikrosk. Anat. Forsch. (Leipz.) 89: 495-511.

Gray, E. G. (1982) Rehabilitating the dendritic spine. Trends Neurosci. 5: 5-6.

Jack, J. J. B., S. J. Redman, and K. Wong (1981) The components of synaptic potentials evoked in cat spinal motoneurons by impulses in single group IA afferents. J. Physiol. (Lond.) 321: 65-96.

Jacobsen, S. (1967) Dimensions of the dendritic spine in the sensorimotor cortex of the rat, cat, squirrel monkey and man. J. Comp. Neurol. 129: 49-58.

Jacobsen, S., and D. A. Pollen (1968) Electrotonic spread of dendritic potentials in feline pyramidal cells. Science 161 : 1351-1353.

Johnston, D. (1981) Passive cable properties of hippocampal CA3 pyramidal neurons. Cell. Mol. Neurobiol. 1: 41-55.

Koch, C., and T. Poggio (1983) A theoretical analysis of electrical properties of spines. Proc. R. Soc. Lond. (Biol.) 218: $455-477$.

Laatsch, R. H., and W. M. Cowan (1966) Electron microscopic studies of the dentate gyrus of the rat. I. Normal structure with special reference to synaptic organization. J. Comp. Neurol. 128: 359-396.

Lam, D. M., and D. Johnston (1982) Active and passive membrane properties of isolated horizontal cells from the catfish retina. Nature 292: 451-453.

Lee, K. S., F. Schottler, M. Oliver, and G. Lynch (1980) Brief bursts of high frequency stimulation produce two types of structural change in rat hippocampus. J. Neurophysiol. 44: 247-258.

Lindsay, R. D., and A. B. Scheibel (1976) Quantitative analysis of dendritic branching pattern of granule cells from human dentate gyrus. Exp. Neurol. 52: 295-310.

Lorente de No, R. (1934) Studies on the structure of the cerebral cortex. II. Continuation of the study of the ammonic system. J. Psychol. Neurol. 46: 255-242.

MacVicar, B. A., and F. E. Dudek (1980) Dye-coupling between CA3 pyramidal cells in slices in rat hippocampus. Brain Res. 196: 494-497.

Mannen, H. (1966) Contribution to the quantitative study of the nervous tissue. A new method for measurement of the volume and surface area of neurons. J. Comp. Neurol. 126: $75-90$.

McNaughton, B. L., C. A. Barnes, and P. Andersen (1981) Synaptic efficacy and EPSP summation in granule cells of rat fascia dentata studied in vitro. J. Neurophysiol. 46: 952966.

Meyer, G., and R. Ferres-Torres (1978) Quantitative Altersabhangige Variation der Dendriten Spines in Hippocampus (CA1, CA3 und Fascia Dentata) der Albinomaus. J. Hirnforsch. 19: 371-378.

Minkwitz, H. -G. (1976a) Zur Entwicklung der Neuronenstruktur des Hippocampus während der Prä- und Postnatalen Ontogenese der Albinoratte. I. Mitteilung: Neurohistologische Darstellung der Entwicklung von Langaxoniger Neurone aus der Regionen CA3 and CA4. J. Hirnforsch. 17: 213231.
Minkwitz, H. -G. (1976b) Zur Entwicklung der Neuronenstruktur des Hippocampus während der Prä- und Postnatalen Ontogenese der Albinoratte. III. Mitteilung: Morphometrische Erfassung der Ontogenetischen Veranderungen in Dendriten-Struktur und Spine Besatz an Pyramiden-Neuronen (CA1) des Hippocampus. J. Hirnforsch. 17: 255-275.

Norman, R. S. (1972) Cable theory for finite length dendritic cylinders with initial and boundary conditions. Biophys. J. 12: $25-45$.

Purpura, D. P. (1974) Dendritic spine "dysgenesis" and mental retardation. Science 186: 1126-1128.

Rall, W. (1959) Branching dendritic trees and motoneuron membrane resistivity. Exp. Neurol. 1: 491-527.

Rall, W. (1967) Distinguishing theoretical synaptic potentials computed for different soma-dendritic distributions of synaptic input. J. Neurophysiol. 30: 1138-1168.

Rall, W. (1974) Dendritic spines, synaptic potency and neuronal plasticity. In Cellular Mechanisms Subserving Changes in Neuronal Activity, C. D. Woody, K. A. Brown, T. J. Crow, and J. D. Knispel, eds., pp. 13-21, Brain Information Service, UCLA, Los Angeles.

Rall, W. (1977) Core conductor theory and cable properties of neurons. In Handbook of Physiology. Section I: The Nervous System, E. K. Kandel, ed., pp. 39-98, Williams and Wilkins, Baltimore.

Rall, W. (1981) Functional aspects of neuronal geometry. In Neurons Without Impulses, A. Roberts and B. M. H. Bush, eds., pp. 223-254, Cambridge University Press, Cambridge, England.

Rall, W., and J. Rinzel (1973) Branch input resistance and steady attenuation for input to one branch of a dendritic neuron model. Biophys. J. 13: 648-688.

Rinzel, J. (1982) Neuronal plasticity (learning). In Lectures on Mathematics in the Life Sciences, R. M. Miura, ed., Vol. 15, pp. 7-25, American Mathematics Society, Providence.

Rinzel, .J., and W. Rall (1974) Transient response in a dendritic neuron model for current injected at one branch. Biophys. J. 14: $759-790$.

Scheibel, M. D., and A. B. Scheibel (1968) On the nature of dendritic spines-Report of a workshop. Commun. Behav. Biol. Part A Orig. Artic. 1: 231-265.

Schwartzkroin, P. A. (1975) Characteristics of CA1 neurons recorded intracellularly in the hippocampal "in vitro" slice preparation. Brain Res. 85: 423-436.

Sholl, D. A. (1953) Dendritic organization in the neurons of the visual and motor cortices of the cat. J. Anat. 87: 387-406.

Stansfield, B. B., and W. M. Cowan (1979) The morphology of the hippocampus and dentate gyrus in normal and reeler mice. J. Comp. Neurol. 185: 393-422.

Swindale, M. V. (1981) Dendritic spines only connect. Trends Neurosci. 4: 240-241.

Turner, D. A. (1982) Soma and dendritic spine transients in intracellularly-stained hippocampal neurons. Soc. Neurosci. Abstr. 8: 945 .

Turner, D. A., and W. H. Calvin (1981) Dendritic analysis of lobster stretch receptor neurons. Cell. Mol. Neurobiol. 1: 189-207.

Turner, D. A., and P. A. Schwartzkroin (1980) Steady-state electrotonic analysis of intracellularly-stained hippocampal neurons. J. Neurophysiol. 44: 184-199.

Valverde, R., and A. Ruiz-Marcos (1969) Dendritic spines in the visual cortex of the mouse: Introduction to a mathematical model. Fxp. Brain Res. 8: 269-283.

Wenzel, J., W. Kirsche, G. Kune, T. Neumann, H. Wenzel, and E. Winkelman (1973) Licht und Electronen Mikroskopische Untersuchungen Uber die Dendriten Spines an Pyramiden- 
Neuronen des Hippocampus (CA1) bei der Ratte. J. Hirnforsch. 13: 387-408.

Wenzel, J., C. Stender, and G. Duwe (1981) The development of the neuronal structure of the fascia dentata of the rat. Neurohistologic morphometric, ultrastructural and experimental investigations. J. Hirnforsch. 22: 629-683.

Westrum, L. E., and T. W. Blackstad (1962) An electron microscope study of the stratum radiatum of the rat hippo- campus (CA1) with particular emphasis on synaptology. J. Comp. Neurol. 119: 281-309.

Wilson, C. J., P. M. Groves, S. T. Kitai, and J. C. Linder (1983) Three-dimensional structure of dendritic spines in the rat neostriatum. J. Neurosci. 3: 383-398.

Wong, R. K. S., and D. A. Prince (1981) Afterpotential generation in hippocampal pyramidal cells. J. Neurophysiol. 45: 86-97. 